\title{
Briefing: Continuous monitoring and adaptive control: the "smart" storm water management solution
}

Jeffrey Wright $\mathrm{PE}, \mathrm{PH}$

Vice President and Water Practice Director, Atkins, Alexandria, VA, USA (corresponding author: jeffrey.wright@atkinsglobal.com)

\author{
Dayton Marchese \\ Water Resources Engineer, OptiRTC, Inc., Boston, MA, USA \\ (Orcid:0000-0002-7207-272X)
}

The approach to managing storm water, and the implementation of storm water infrastructure, has not kept pace with the digitally enabled environment. Since the first run-off systems designed in ancient times, moving storm water away from cities to protect life and property has been the primary concern - out of sight, out of mind. The engineering and science community agree: extreme weather events and climatic conditions such as floods and droughts are more likely in the future. To keep up, the built environment is changing by integrating smart technologies and holistic approaches to infrastructure design and management. Regulations for the mitigation of pollution caused by urban run-off require more accuracy than those in the past. Future water resources design must adapt to these new conditions. Adaptation includes using smart systems, such as continuous monitoring and adaptive control, to repurpose the existing infrastructure and build modern systems that harness storm water's latent value - changing what was once thought of as a liability into an asset.

\section{Introduction}

Existing storm water infrastructure is ordinarily passive and often serves a limited purpose. The design and construction of these systems rely on fixed site configurations and predetermined static flow scenarios to provide a single management objective (e.g. flood risk mitigation, water quality improvement or channel protection). Once constructed, the systems require perpetual operation and maintenance (O\&M), with limited future benefit; in fact, they often act as a liability as communities continue to pay for antiquated benefits while modern-day costs increase. New storm water management systems face these same design and construction limitations because they rely on the same passive design methodology and implementation to achieve current regulatory requirements, only to become substandard as environmental and regulatory conditions evolve (Barbosa et al., 2012).

Two of the dominant, and often opposing, functions of storm water infrastructure are conveyance (i.e. moving storm water from one place to another) and storage (i.e. detaining or retaining water on-site). Storm water conveyance infrastructure (e.g. pipe systems and channels) helps reduce localised flooding by removing water from developed areas as quickly as possible. Storm water storage infrastructure (e.g. ponds and underground basins) provides downstream channel protection and flood risk mitigation by limiting discharge rates and improves water quality by facilitating pollutant-removal processes prior to the release of water. Developing infrastructure that meets these opposing functions has traditionally been a challenge.

Continuous monitoring and adaptive control (Cmac) systems provide a practical solution to enhance the performance and value of existing storm water infrastructure and increase the efficacy and efficiency of new infrastructure (Lefkowitz et al., 2016).
Cmac storm water systems leverage the communications technology known as Internet of Things to integrate site data (e.g. water level and discharge) from field-deployed environmental sensors with real-time weather forecast information to directly monitor performance and actively control storm water storage and flows (Figure 1). For example, a Cmac storm water pond preparing for a future rain event would analyse the forecast storm size, compare the incoming run-off volume to the available storage capacity in the pond and discharge water until the storm could be fully captured (Roman et al., 2017). Cmac systems are adaptive and more efficient, converting storm water infrastructure into an asset, instead of a liability, even when considering the long-term O\&M costs. Through Cmac, existing storm water infrastructure can be enhanced or repurposed, new storm water infrastructure can provide better benefits and both can provide a higher return on investment by managing more storm water volume to the design standards.

Three significant challenges face current storm water management systems. First, measurement and performance reporting communities need accurate reports on performance to meet regulatory compliance requirements. Second, operations and maintenance - there is a need to reduce ongoing costs and achieve sustained performance. And third, multipurpose management communities need solutions that are adaptive and scalable to address changing watershed conditions and meet multiple desired storm water management outcomes. Cmac provides a cost-effective and adaptive solution to all three challenges.

\section{Measuring and reporting performance}

Regulatory agencies will soon require communities to provide consistent, accurate and reliable data on the performance of their storm water systems to demonstrate compliance, including metrics 


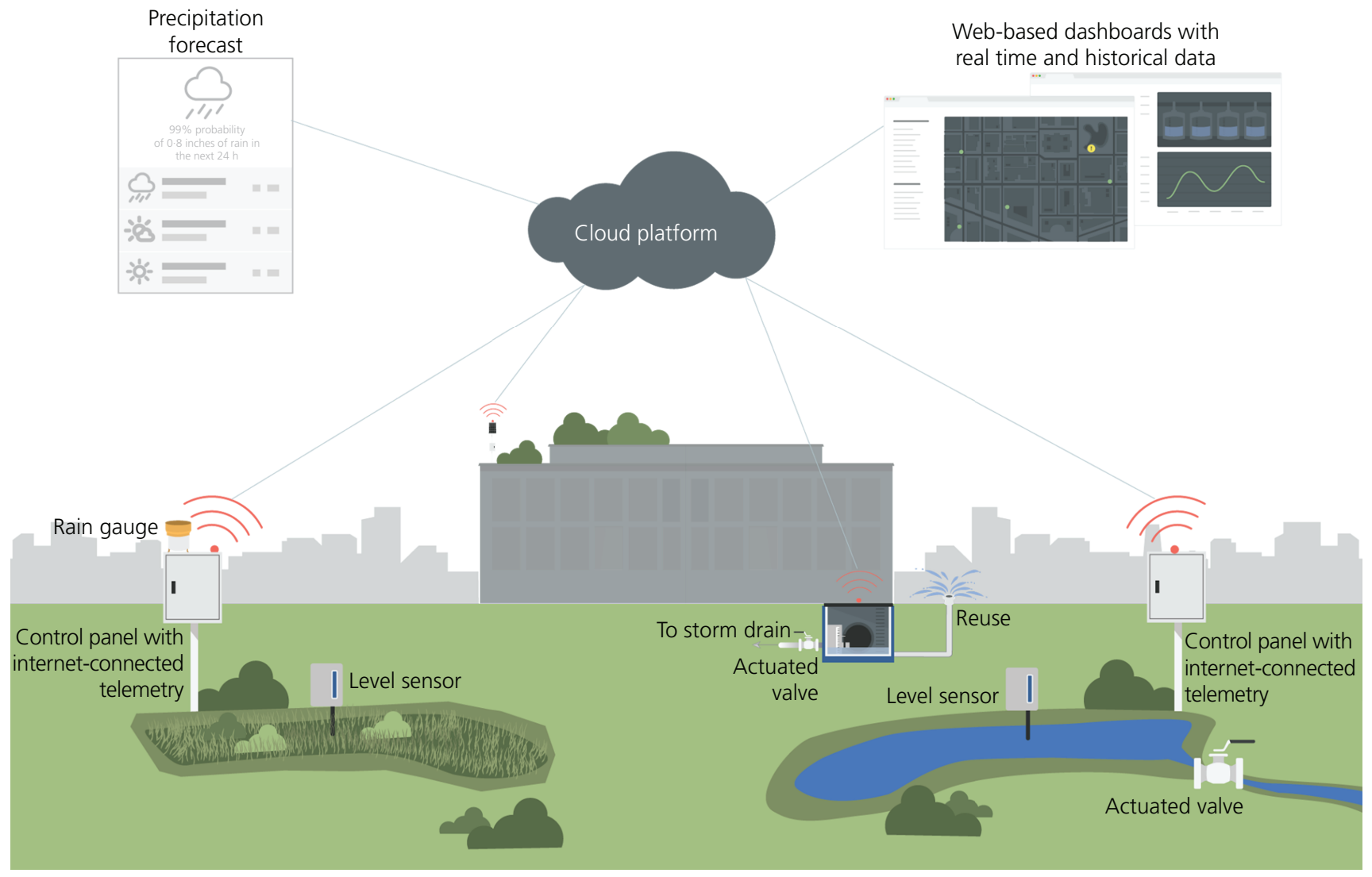

Figure 1. Cmac diagram. Information is integrated from field-deployed environmental and water-level sensors, actuated valves, telemetryenabled control panels with cloud-based control systems and real-time weather forecast data to monitor performance directly and actively control storm water storage and flows (figure from Atkins)

such as nutrient removal efficiency or peak discharge (National Research Council, 2009). Collecting, collating and reporting these data are currently not feasible due to limited resources and technology. Common practice in storm water management is to use design standards as proxies for performance metrics. For example, the static design volume of a storm water detention pond can be used as a proxy for nutrient removal efficiency larger capture volume yields a longer hydraulic residence time, resulting in a higher removal efficiency (Benjamin and Lawler, 2013). However, the use of design standards as proxies for performance assumes that after construction, storm water infrastructure will function indefinitely as designed. Due to adverse site conditions, changing environments and unidentified failures, this assumption of perfect functionality is often incorrect (Blecken et al., 2017) and introduces risk as the claimed level of performance is not delivered.

Cmac technology provides the necessary data for accurately recording and reporting on storm water infrastructure performance. Because Cmac uses real-time site information - often one data point per minute per sensor (Lefkowitz, 2017) - these systems obtain high-quality performance data, efficiently collated and readily reported to regulators. Cmac's ability to provide accurate, real-time data for the performance of the system, and the source and concentration of pollutants, will give communities and regulators an unprecedented level of accuracy when evaluating the success of their storm water infrastructure.

\section{Operations and maintenance}

Current periodic or schedule-driven O\&M activities are inefficient and typically result in higher maintenance costs. Cmac technology allows communities to manage their storm water infrastructure more proactively and efficiently through targeted O\&M activities. Because Cmac continuously monitors performance, anomalous behaviour (e.g. an underground basin losing water faster than expected) can be automatically identified and targeted action (e.g. fixing an identified leak) can be taken before system failure. This targeted O\&M makes Cmac systems more efficient and better maintained, thus reducing cost.

Another way in which Cmac improves O\&M is through intelligent asset management. Data-driven analysis and decision making dramatically improve many routine O\&M activities for managing storm water assets, increasing uptime and decreasing O\&M costs. Adaptive and proactive maintenance through the integration of asset management tracking systems allows the community to maintain 
assets, addressing their needs before they fail. System performance information is integrated into maintenance contractor workflows and work order management, which helps target maintenance requirements, minimising unplanned maintenance and associated downtime by alerting staff when a facility is operating outside its expected performance limits or specifications.

\section{Beyond single-purpose management}

One of the shortcomings of traditional storm water infrastructure is that each facility functions for a limited purpose (flood control, channel protection, water quality etc.), meaning that more resources (e.g. property, funding and time) are required to meet the multiple objectives towards which many communities are now working. By installing smart technology and hardware, communities can enhance or convert existing storm water infrastructure, improving water quality and significantly expanding capacity.

Cmac technology helps communities adapt to changing conditions, unlocking the potential to achieve multiple storm water management goals and outcomes. Facilities that integrate Cmac can now meet many performance metrics, instead of one or two. For example, consider a dry storm water detention pond that provides downstream channel protection and flood control, but little to no water quality benefit (Balascio and Lucas, 2009) due to having a relatively short hydraulic residence time. By implementing Cmac on a dry detention facility, water can be retained (e.g. by automatically closing an actuated valve) during and after a storm event, thereby increasing hydraulic residence time and water quality performance, without compromising the flood control and channel protection benefits because the pond is automatically drained before the next incoming storm.

With Cmac, the function and performance of storm water infrastructure are easily modified, at minimal capital cost, thus adapting to changing climatic and hydrologic conditions. In many cases, functional modification is achieved by changing a setting in the Cmac software (e.g. programming a storm water basin to have a longer postevent retention time or a shorter drawdown time) (Lefkowitz, 2017). Due to this programmable logic, Cmac allows the system to meet its intended performance measures and scale or adjust to new ones.

In new facilities, the active and dynamic control of system performance meets storm water management objectives more efficiently by simultaneously measuring quantity, volume and quality control. Cmac allows storm water infrastructure to accomplish more with less - using a much smaller physical footprint, thus reducing land acquisition (or loss of developable space) and construction cost.

\section{Relevant application of Cmac}

One such application of Cmac technology, developed and delivered by OptiRTC, Inc., has been successfully implemented in the city of Philadelphia, by the Philadelphia Water Department (PWD). Philadelphia is one of 860 US municipalities with a combined sewer system (CSS) (see EPA, 2018), the overflows (i.e. discharge of storm water combined with municipal waste to natural waters) from which represent a major source of water pollution. To address this issue of combined sewer overflow (CSO), Philadelphia implemented Green City, Clean Waters, a long-term control plan to reduce storm water pollution currently entering their CSS using green infrastructure. In particular, PWD, along with the Philadelphia Industrial Development Corporation, incentivises commercial property owners to implement storm water mitigation solutions through the Stormwater Management Incentives Grant Program (SMIP).

In November 2016, PWD awarded SMIP grant funding for Cmac to be implemented on a $3 \cdot 2$ ha commercial property within the city's combined sewer area (Lefkowitz, 2017). The property's existing retention pond was not meeting PWD's current storm water management standards, thus contributing to potential CSOs. The implementation of Cmac included installing a real-time water level sensor in the pond, an actuated valve on the control structure and a communications and control panel connecting the water level sensor and actuated valve to a cloud-computing platform. Programmable logic for the pond includes pre-event drawdown (i.e. opening the actuated valve before a storm to drawdown the water and create additional storage capacity) and postevent retention (i.e. closing the actuated valve during and after a storm).

A performance review of the installation after 6 months of operation revealed that the Cmac system exceeded PWD's criteria for wet weather discharge by completely avoiding wet weather outflow for nearly all rain events (see Lefkowitz, 2017 for supporting analysis). During the 6-month period, a total of $50.8 \mathrm{~cm}$ of precipitation fell, which is typical for Philadelphia. Using Cmac, PWD was able to keep $10220 \mathrm{~m}^{3}$ of water out of the city's CSS during the storms, which accounted for $98.8 \%$ of total run-off on the property, while also controlling dry weather discharge effectively. By comparison, a passive system with the same hydraulic and hydrologic conditions would have only prevented $35 \%$ wet weather flow. The use of this technology has allowed PWD to reduce implementation time, cost and risk while also providing the stakeholders with real-time performance data to help shape the design for future projects and increasing infrastructure resiliency in a changing environment.

\section{Conclusion}

Forecast-based real-time control technologies, such as Cmac, of both connected and distributed storm water infrastructures allow for adaptive management by integrating information from field-deployed sensors with real-time weather forecast data to directly monitor performance and actively control storage and flows. Improved metrics and performance reporting by way of centralised cloudbased control systems help communities predict and plan for O\&M costs and comply with regulatory requirements. Moreover, Cmac allows communities to operate and maintain their infrastructure systems and components more efficiently and achieve multiple storm water management objectives and associated regulatory compliance targets while reducing capital and operating costs. 
Smart Infrastructure and Construction

Volume 170 Issue SC4
Briefing: Continuous monitoring and

adaptive control: the 'smart' storm water

management solution

Wright and Marchese
In the past, storm water management systems were designed with only one purpose in mind - move the water away from cities and structures as quickly as possible. It was an inelegant solution - shortsighted, but useful for a time. Now those 'dumb' infrastructure solutions can be turned into 'smart' systems - protecting communities from flooding, increasing water quality and maintaining storm water systems more efficiently.

\section{REFERENCES}

Balascio CC and Lucas WC (2009) A survey of storm-water management water quality regulations in four mid-Atlantic states. Journal of Environmental Management 90(1): 1-7, http://dx.doi.org/10.1016/ j.jenvman.2007.10.006.

Barbosa AE, Fernandes JN and David LM (2012) Key issues for sustainable urban stormwater management. Water Research 46(20): 6787-6798, http://dx.doi.org/10.1016/j.watres.2012.05.029.

Benjamin MM and Lawler DF (2013) Water Quality Engineering: Physical/Chemical Treatment Processes. Wiley, Hoboken, NJ, USA.
Blecken GT, Hunt III WF, Al-Rubaei AM, Viklander M and Lord WG (2017) Stormwater control measure (SCM) maintenance considerations to ensure designed functionality. Urban Water Journal 14(3): 278-290, http://dx.doi.org/10.1080/1573062X.2015.1111913.

EPA (US Environmental Protection Agency) (2018) Combined Sewer Overflows (CSOs). EPA, Washington, DC, USA. See https://www.epa.gov/npdes/combined-sewer-overflows-csos (accessed 03/03/2018).

Lefkowitz J (2017) From passive to dynamic storage. WE\&T Magazine, July, pp. 46-51.

Lefkowitz J, Sarmanian A and Quigley M (2016) Continuous monitoring and adaptive control - the internet of things transforms stormwater management. Journal of the New England Water Environment Association 50(1): 44-51.

National Research Council (2009) Urban Stormwater Management in the United States. National Academies Press, Washington, DC, USA.

Roman D, Braga A, Shetty N and Culligan P (2017) Design and modeling of an adaptively controlled rainwater harvesting system. Water 9(12): 974, http://dx.doi.org/10.3390/w9120974.

\section{How can you contribute?}

To discuss this paper, please email up to 500 words to the editor at journals@ice.org.uk. Your contribution will be forwarded to the author(s) for a reply and, if considered appropriate by the editorial board, it will be published as discussion in a future issue of the journal.

Proceedings journals rely entirely on contributions from the civil engineering profession (and allied disciplines). Information about how to submit your paper online is available at www.icevirtuallibrary.com/page/authors, where you will also find detailed author guidelines. 